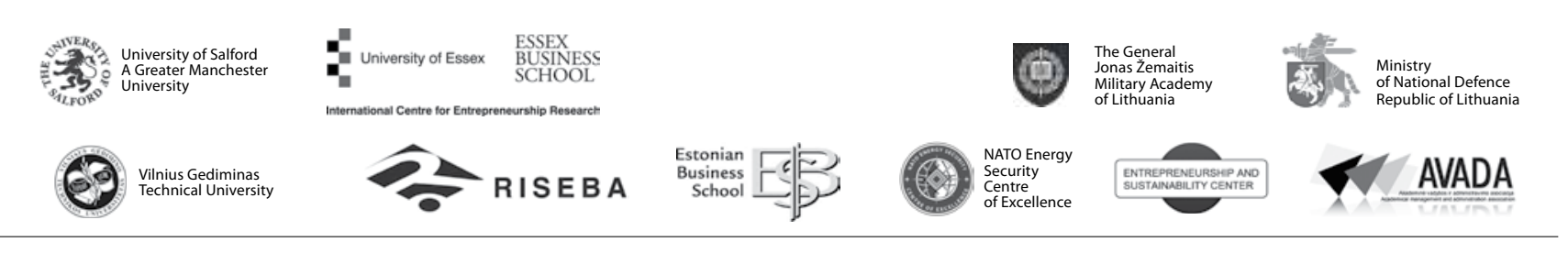

\author{
JOURNAL OF SECURITY AND SUSTAINABILITY ISSUES \\ ISSN 2029-7017 print/ISSN 2029-7025 online \\ 2018 June Volume 7 Number 4 \\ https://doi.org/10.9770/jssi.2018.7.4(9)
}

\title{
TOWARDS SUSTAINABLE AND SECURE DEVELOPMENT: ENERGY EFFICIENCY PECULIARITIES IN TRANSPORT SECTOR
}

\author{
Manuela Tvaronavičiené $\dot{e}^{1,2}$ \\ ${ }^{1}$ Department of Management, General Jonas Zemaitis Military Academy of Lithuania, \\ Silo 5A, LT-10332, Vilnius, Lithuania \\ ${ }^{2}$ Department of Business Technologies and Entrepreneurship, Vilnius Gediminas Technical University of Lithuania, \\ Sauletekio 11, LT-10223, Vilnius, Lithuania \\ E-mail: manuela.tvaronaviciene@vgtu.lt
}

Received 18 Janauary 2018; accepted 15 April 2018

\begin{abstract}
Sustainable and secure development of any country is considerably affected by energy efficiency of economy. Efforts directed to diminishing of energy resources consumed have to be directed to achieving multiple goals, ultimately impacting demand in energy resources. Hence, ultimate demand of energy resources depend on economic growth rates, economy structure, technological level, distribution of income and behavioral patterns, both of business companies and households. This paper is devoted to analysis of energy efficiency in transport sector of three secected European countries. The methodology of research is based on comparison on long-term tendencies of energy intensity in transport equipment segment. The long-term forecasting untill year 2050 will be performed by using LEAP (the Long-range Energy Alternatives Planning system) software; ceteris paribus assumption will be selected. The countries selected for analysis are: Belgium, Bulgaria and Lithuania. The selected countries, we assume, would represent better developed Europea countries (represented by e.g. Belgium), and comparitively less developed European countries of different size (represented by Bulgaria and Lithuania). The juxatopsing of energy intensity change in long run, revealing mode of this change and comparison of cases of selected countries, would allow to reveal if energy efficiency of transport equipment converge. Since trnasport equipment sector embraces various modes of transport, additionally public roads sector will be tackled. We believe, that results obtained will signal what policy implications, if any, are necessary in order to direct transport users towards stewardship of energy resources through increase of efficiency of conventional energy resources and transfer to renewables in the nearest future.
\end{abstract}

Keywords: sutainable and secure development; energy intensity; transport; Belgium; Bulgaria; Lithuania

Reference to this paper should be made as follows: Tvaronavičienė, M. 2018. Towards sustainable and secure development: energy efficiency peculiarities in transport sector, Journal of Security and Sustainability Issues 7(4): 719-725.

https://doi.org/10.9770/jssi.2018.7.4(9)

JEL Classifications: Q01, Q28

\section{Introduction}

Thre is a lot of attention recently paid to multiple facets of sustainable development. Efficient consumption of energy is especially closely related to the aim of maintaining a sequent path towards gradual economic growth and more affluent future not to be followed by deteriorated environment in which we live. There is a lot of the latest literature devoted to both, to energy efficiency issues (Tvaronavičienė et al. 2015; Tvaronavičienė 2016; Melas et al.; Abrhám 2017; Tvaronavičienè et al. 2018) and concerns related to use of various sources of energy (Genys, D.; Krikštolaitis, R. 2017; Popp et al. 2018; Shakhovskaya et al. 2018). Going further, consumption of energy and composition of energy sources used (so called energy mix) affects not only of sustainability of de- 
velopment, understood as economic development implemented with concern of environment sensitivity to pollution caused by development itself); consumption of energy currently is related to security of development. To put it in other way concerns about sustainable development has been transformed into concerns of sustainable and secure development (Tetsman et al. 2017; Kuril 2018; Tvaronavičienė 2018). Security facet here embraces energy security facets, which is a separate area of research. In the context of this research let us indicate that availability of energetic sources is one of key components of energy security. We could clearly state therefore that efficient energy consumption has become precondition not only of sustainable but of secure development as well.

\section{Fundamental relationships between economic growth, energy consumption and pollution. Role of renewables and energy efficiency}

Let us recall, what energy efficiency means. Energy efficiency is estimated by quantity of energy needed to perform one or another activity. Depending on technological process, level of technological advance for the same activity different quantities of energy can be used. Here is explanation of energy efficiency, provided by An office of U.S. Department of Energy "Energy efficiency refers to the activity or product that can be produced with a given amount of energy; for example, the number of tons of steel that can be melted with a megawatt hour of electricity. At the level of a specific technology, the difference between efficiency and energy intensity is insignificant - one is simply the inverse of the other. In this example, energy intensity is the number of megawatt hours used to melt one ton of steel.

At the level of the aggregate economy (or even at the level of an end-use sector) energy efficiency is not a meaningful concept because of the heterogeneous nature of the output. The production of a huge number of goods, the mixing of the transport of freight and people, and the variety of housing and climates makes an aggregate energy intensity number based on Gross Domestic Product (GDP), a number that disguises rather than illuminates. A simple intensity measure can be calculated (as Energy/GDP), but this number has little information content without the underlying sector detail.

The distinction between energy intensity and energy efficiency is important when multiple technologies or multiple products underlie what is being compared. While it would not be sensible to compare the energy efficiency of steel production with the energy efficiency of ethanol production, it is possible to examine the energy intensity of all manufacturing." (An office of U.S. Department of Energy https://www.energy.gov/eere/ analysis/energy-intensity-indicators-efficiency-vs-intensity).

Hence, despite we strive for energy efficiency, indicator used for its estimation is specifically "energy intensity". In our research we will compare forecasted energy intensities for transport sector of selected countries in order to reveal if that sector can be considered as equally (or not) efficient for different countries. If it appeared that forecasted for long-run (until year 2050) energy intensity is rather similar in taken countries we would conclude that energy efficiency converges. In classic economic theory it is claimed that majority of processes should converge, alas in reality this consistent pattern of development is being distorted by various forces. Returning to our research, if forecasted ceteris paribus energy intensity would differ considerably in selected countries, we would conclude that additional economic tools should be introduced into economic policy in order to facilitate conversation processes of energy intensity by pushing this indicator down by available economic policy instruments.

After clarification of meaning of energy efficiency and energy intensity and discussing rationale behind of juxtaposing of forecasted energy intensity results in long-run, let us list factors affecting level of energy intensity in economy of any country.

Here let us recall the fundamental relationship between economic growth and energy use: the more a country develops economically, the higher demand is for energy. Economic development inevitably is being followed by increase in energy use. If a country relies e.g. on oil or gas in its development process then availability and 
affordability of those non-replenishable resources starts playing a role of increasing significance. Let us add here all infrastructure, which is needed to supply those energy sources to European country, let say. Here we start encountering with one more issue, i.e. protection of "critical infrastructure" (Šincāns et al. 2016; Plèta et al. 2018). Besides problems related to supply of energy, which is needed for economic growth, we encounter consequences of enhanced energy use. There is another consistent pattern, which is known as Kuznets curve. It says that the use on energy causes pollution of environment emitting $\mathrm{CO}_{2}$, and other gases (called green gases) deteriorating our planet. At the certain point this pollution is being curbed, therefore Kuznets curve looks like inverted $U$ instead of straightly increasing line. Alas, this bending of the inserted $U$ down is not natural phenomenon. It is caused by economic policy tools enforcing companies use technologies protecting environment from degradation, deterioration. Therefore switch to renewable energy is one of tools of tremendous importance, which could facilitate preservation of our planet in the era of economic growth. Parallel to energy efficiency, which will be estimated via energy intensity indicator, has to be sequent increase via all possible means: technology, behavioral change directed towards energy stewardship, and economic policy, if necessary.

\section{Materials and methods for analysis of forecasted energy intensity of transport in selected countries}

Total energy intensity of a whole country depends on many factors, such as economic structure (different sectors of economy has energy intensity determined by technological process), behavior of households, which heat and cool their houses, use various appliances and equipment, use transport means. Ultimate aim of any society is, as it was already mentioned above, is to use energy as efficient as possible and to switch to renewable energy. Technological advance and attitudes play crucial role in the process of increase of energy efficiency at society level (Oganisjana et al. 2017; Jankalová, Jankal 2017; Zemlickiene et al. 2017; Radwan, Sakr 2017).

In this paper we will tackle specifically transport sector. Our aim is to clarify how energy intensity is going to change in this sector until year 2050 making ceteris paribus assumption. Let us recall that ceteris paribus assumption means that external conditions remain the same, i.e. GDP growth rate, population growth, economy structure, technology level, energy mix etc. If we decided to change this assumption, we already had modeling case. Than each assumption had be grounded, naturally. Below we introduce forecasting results, which were obtained by application of LEAP (the Long-range Energy Alternatives Planning system) software.

Let us examine long-term energy intensity change in transport sector of Belgium (Figure 1), Bulgaria (Figure 2) and Lithuania (Figure 3). 
Transport Equipment: Final Energy Intensity (Tonnes of Oil Equivalent per European Euro) Scenario: Baseline, Region: Belgium

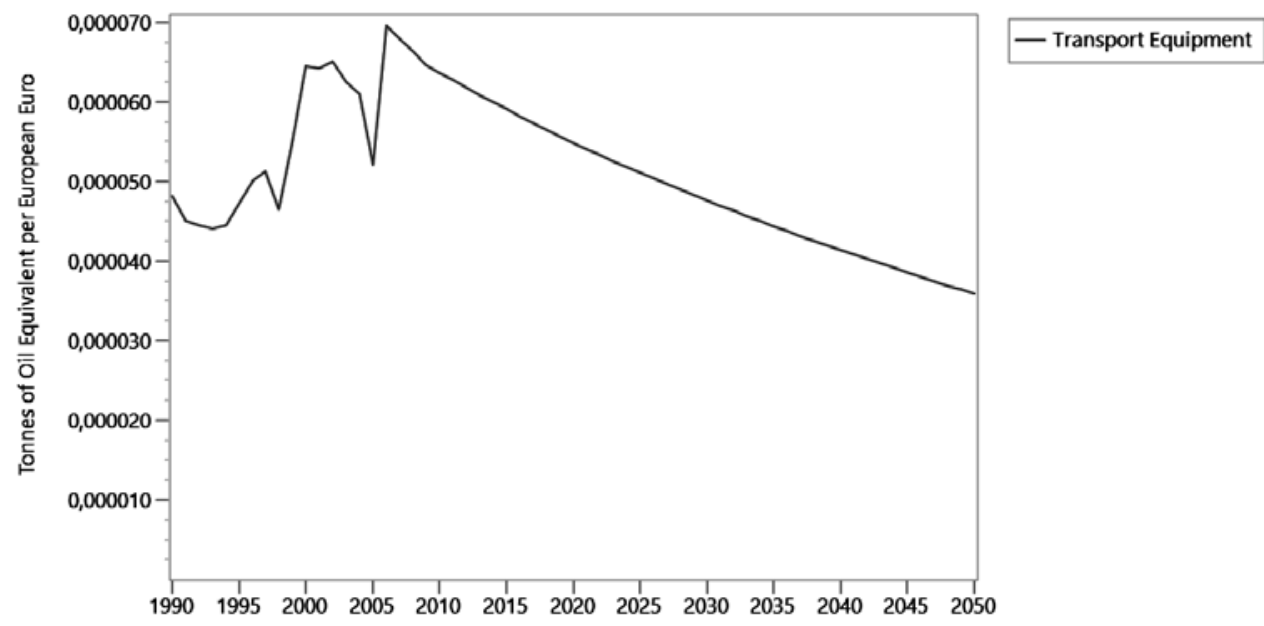

Figure 1. Forecasted energy intensity in transport sector of Belgium until year 2050

Transport Equipment: Final Energy Intensity (Tonnes of Oil Equivalent per European Euro) Scenario: Baseline, Region: Bulgaria

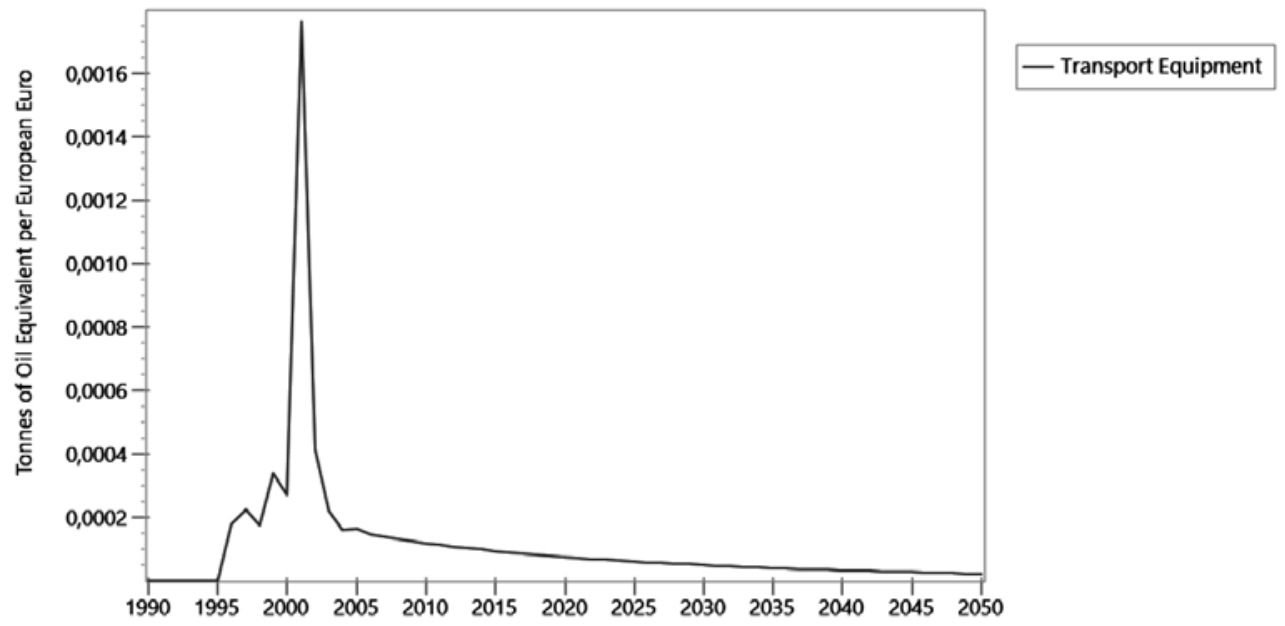

Figure 2. Forecasted energy intensity in transport sector of Bulgaria until year 2050 


\section{Transport Equipment: Final Energy Intensity (Tonnes of Oil Equivalent per European Euro) Scenario: Baseline, Region: Lithuania}

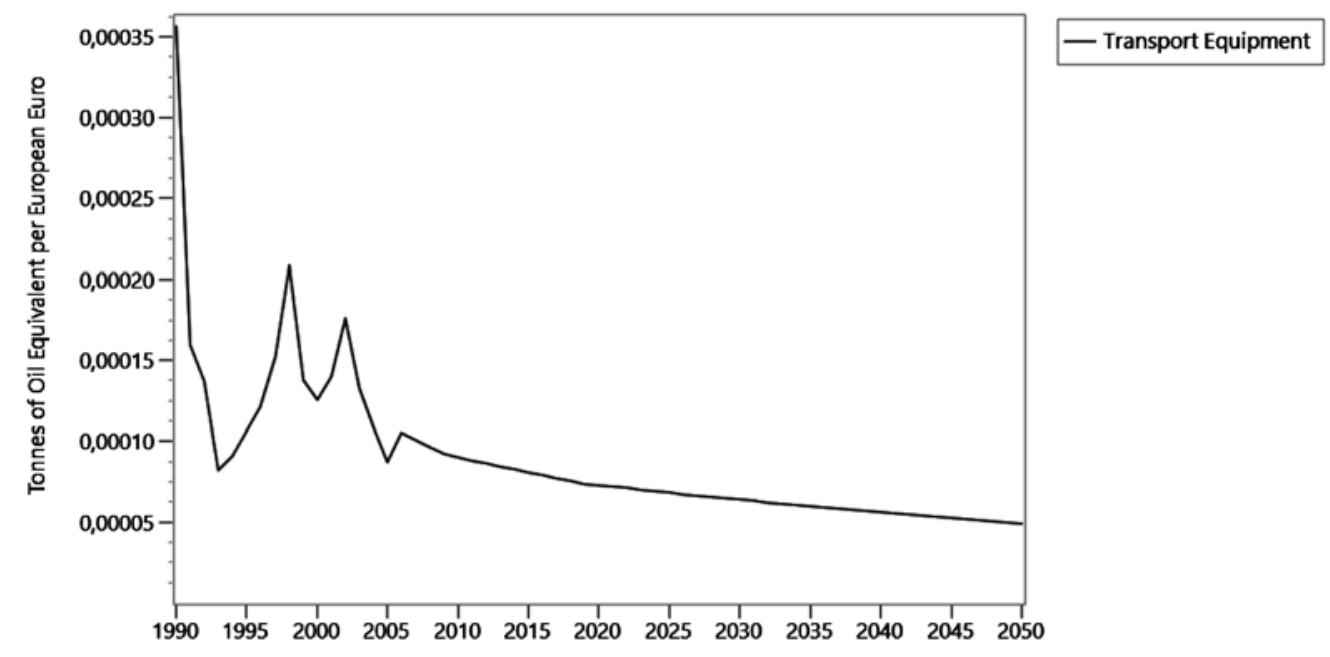

Figure 3. Forecasted energy intensity in transport sector of Lithuania until year 2050

Before providing comments on the results of long-term forecasting let us clarify what is being embraced by transport by software LEAP, which has been used for obtaining of provided results. Hence, in the software used, it is assumed that the transport of each country is composed out of the following groups: "Passenger, Freight, An International, Pipelines, Non Specified" (LEAP the Long-range Energy Alternatives Planning system). Here we examine the change of energy intensity of the whole sector, therefore energy intensities of those "sub-sectors" are incorporated into the the resulting energy intensity of the transport sector. Natural question here may arrise about difference of composition of this sector in selected and any other countries. It is well known that diffeent activities have will have differing energy intensities, and if to take an enegy intensity of a sector incorporating those subsectors, then the total energy entensity would be affected by shares of activities, characterised by higher or lower energy intensities. We admit, that it is limtation of the research. Nevertheless, another insight is, that this limitation of research is of rather general character and is present in all researches, where energy intensities of any economic sectors, which is inevitably is comprised of specific activities, are compared.

\section{Results}

Hence, the results of forecasting allow us to come to the following insights. The first, for all selected countries diminishing energy intensity in long run, i.e. until year 2050, is characteristic. The second, the countries' transport sectors currently have differ energy intensities; the differences, judging from the forecasted results, would remain rather significant in year 2050. We can observe, that Final energy intensity, measured in tonnes of oil equivalent per European Euro in Belgium currently has value of a bit above 0,0005 estimated, while, in Bulgaria this value is much higher and equals to 0,001 approximately. In Lithuania energy intensity is higher than in Belgium, but is of the comparable level to it: 0,0007 estimated. To conclude Bulgaria is significantly lagging behind in the area of energy intensity of transport sector. In the long run, all countries are expected to diminish their energy intensity, alas the ultimately reached energy intensity level signals about reserves for improving for Bulgaria in the considered area.

The concluding insights may be tested by providing forecasted share of road traffic activity (passenger public road) in the analyzed countries: Belgium (Figure 4), Bulgaria (Figure 5). We skip Lithuanian case here, since the results of modelling resemble the obtain data for Belgium. 


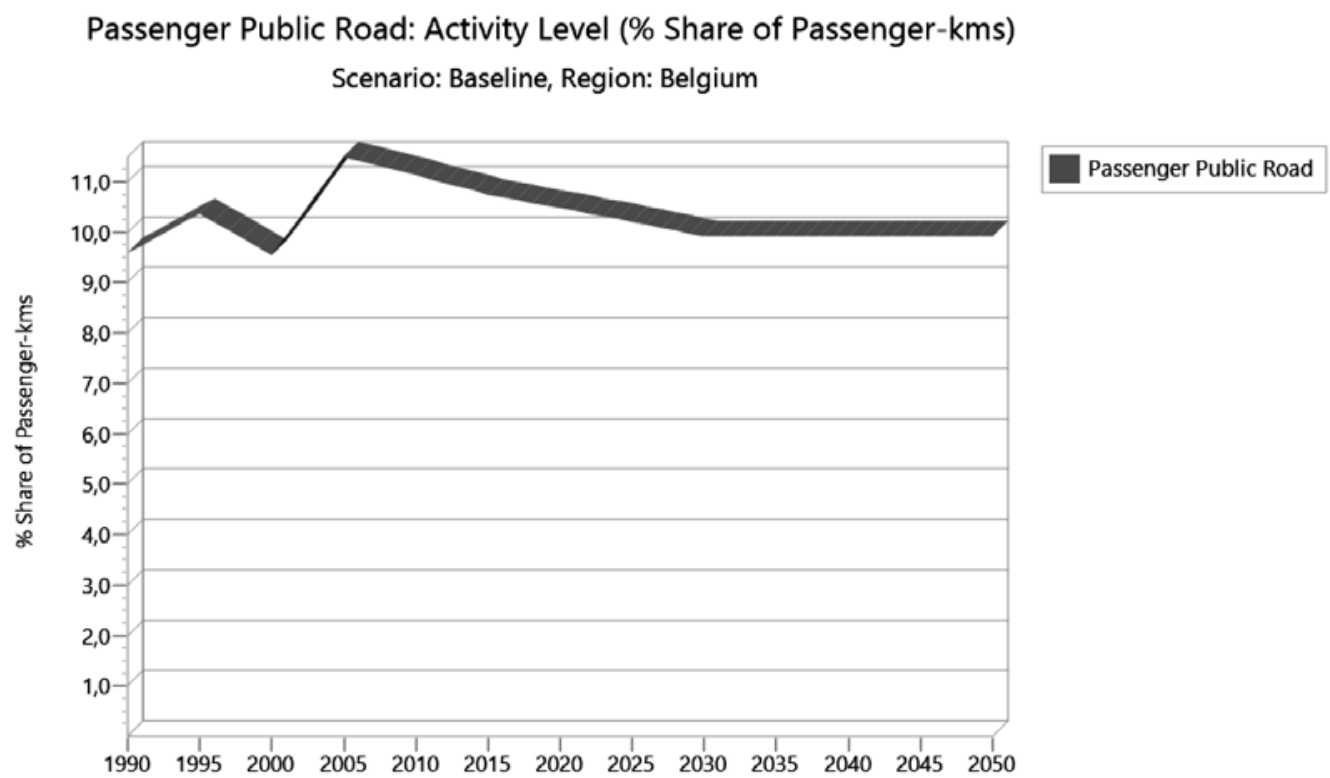

Figure 4. Forecasted share of road traffic activity (passenger public road) in Belgium until year 2050

\section{Passenger Public Road: Activity Level (\% Share of Passenger-kms)} Scenario: Baseline, Region: Bulgaria

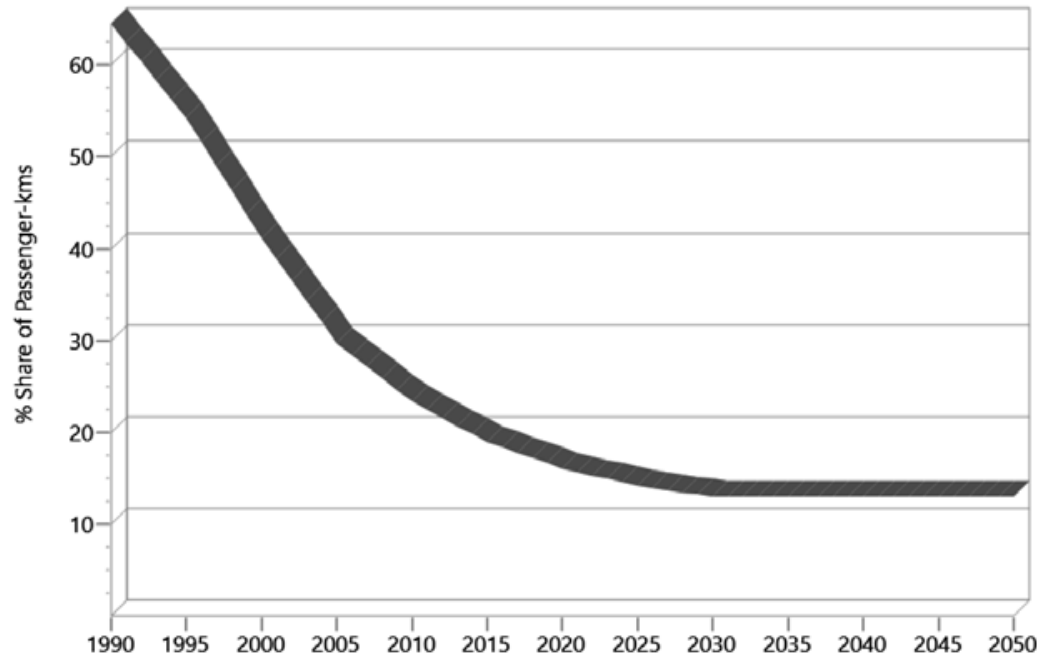

Passenger Public Road

Figure 5. Forecasted share of road traffic activity (passenger public road) in Bulgaria until year 2050

The long-term modeling results partly reflect the current and future structure of transport sector in selected countries. We can observe that currently (in year 2018) the transport structure, if to judge from road traffic activity is rather similar in all selected countries (let us recall, that as it was already mentioned above, Lithuanian data is very similar to Belgium's one). This observation supports insights formulated above generalizing current and expected situation in the area of transport energy intensity of Belgium, Bulgaria and Lithuania. Besides, one more insight could be suggested: it is expected that transport structure in the selected countries would converge. This prospect serves as additional supporting evidence for provided insights. 


\section{Discussions}

Revealed differences in level of energy intensity of considered European countries naturally is followed by further discussion of factors impacting energy efficiently in overall economies, and the analyzed sector, specifically. The following factors, not elaborated above could be indicated (let us recall that in our research we focused on structure of a sector, as a factor affecting total energy intensity of a sector). Hence, the energy intensity in economy, including transport sector, is affected by distribution of income (Tvaronavičiené, Gatautis 2017; Dirzyte et al. 2017); both technological and social innovations, technology transfer capacity (Razminiené et al. 2016), social responsibility level (Dobrovolskienè et al. 2017). In order to make those factors work, respective economic policies have to be adopted. There are already a lot of good practises, which could be adopted, e.g. subsidies to renewable fuel and cars using renewable energy, subsidies for purchasing of electronic vehicles, free public transport etc. Besides social marketing could be employed, which would increase awareness of society of consequences of high energy intensities, which mean extensive energy use.

All those factors, affecting energy intensity has to become focus of discussion to be it scientific discussion, discussion at governmental or societal levels.

\section{References}

Abrhám, J.; Britchenko, I.; Jankovic, M.; Garškaitè-Milvydienė, K. 2018. Energy security issues in contemporary Europe, Journal of Security and Sustainability Issues 7(3): 387-398. https://doi.org/10.9770/jssi.2018.7.3(1)

An office of U.S. Department of Energy https://www.energy.gov/eere/analysis/energy-intensity-indicators-efficiency-vs-intensity

Dirzytė, A.; Rakauskienè, O. G.; Servetkienè, V. 2017. Evaluation of resilience impact on socio-economic inequality, Entrepreneurship and Sustainability Issues 4(4): 489-501. https://doi.org/10.9770/jesi.2017.4.4(7)

Dobrovolskienė, N.; Tvaronavičienė, M.; Tamošiūnienė, R. 2017. Tackling projects on sustainability: a Lithuanian case study, Entrepreneurship and Sustainability Issues 4(4): 477-488. https://doi.org/10.9770/jesi.2017.4.4(6)

Genys, D.; Krikštolaitis, R. 2017. The public perception of nuclear energy in Lithuania, Journal of Security and Sustainability Issues 7(1): 17-25. https://doi.org/10.9770/jssi.2017.7.1(2)

Jankalová, M.; Jankal, R. 2017. The assessment of corporate social responsibility: approaches analysis, Entrepreneurship and Sustainability Issues 4(4): 441-459. https://doi.org/10.9770/jesi.2017.4.4(4)

Kuril, J. 2018. Public administration for safe and secure environment: case of Slovak Republic, Entrepreneurship and Sustainability Issues5(3): 493-501. https://doi.org/10.9770/jesi.2018.5.3(6)

LEAP (the Long-range Energy Alternatives Planning system) https://www.energycommunity.org/default.asp?action=introduction

Melas, V.; Lisin, E.; Tvaronavičienè, M.; Peresadko, G.; Radwański, R. 2017. Energy security and economic development: renewables and the integration of energy systems, Journal of Security and Sustainability Issues 7(1): 133-139. https://oi.org/10.9770/ jssi.2017.7.1(11)

Oganisjana, K.; Svirina, A.; Surikova, S.; Grīnberga-Zālīte, G.; Kozlovskis, K. 2017. Engaging universities in social innovation research for understanding sustainability issues, Entrepreneurship and Sustainability Issues 5(1): 9-22. https://doi.org/10.9770/jesi.2017.5.1(1)

Plèta, T.; Karasov, S.; Jakštas, T. 2018. The means to secure critical energy infrastructure in the context of hybrib warfare: the case of Ukraine, Journal of Security and Sustainability Issues 7(3): 567-578. https://doi.org/10.9770/jssi.2018.7.3(16)

Popp, J.; Kot, S.; Lakner, Z.; Oláh, J. 2018. Biofuel use: peculiarities and implications, Journal of Security and Sustainability Issues 7(3): 477-493. https://doi.org/10.9770/jssi.2018.7.3(9)

Radwan, A.; Sakr, M. M. 2017. Review of Egypt Science and Technology System: SWOT analysis, Entrepreneurship and Sustainability Issues 5(2): 204-211. https://doi.org/10.9770/jesi.2017.5.2(3)

Razminienè, K.; Tvaronavičienè, M.; Zemlickienė, V.. 2016. Evaluation of cluster efficiency tool, Terra Economicus 14(3): 101-111. http://dx.doi.org/10.18522/2073-6606-2016-14-3-101-111

Shakhovskaya, L.; Petrenko, E.; Dzhindzholia, A.; Timonina, V. 2018. Market peculiarities of natural gass: case of the Pacific Re- 